\title{
Landscape Network Approach to Assess Ecological Impacts of Road Projects on Biological Conservation
}

\author{
LIU Shiliang ${ }^{1}$, DENG Li ${ }^{1}$, CHEN Liding ${ }^{2}$, LI Junran ${ }^{3}$, DONG Shikui ${ }^{1}$, ZHAO Haidi ${ }^{1}$ \\ (1. School of Environment, Beijing Normal University, Beijing 100875, China; 2. State Key Laboratory of Urban and Regional Ecology, \\ Research Center for Eco-Environmental Sciences, Chinese Academy of Sciences, Beijing 100085, China; 3. Department of Geosciences, \\ College of Engineering and Natural Sciences, University of Tulsa, Oklahoma 73126, USA)
}

\begin{abstract}
Awareness of the adverse ecological effects of road and other large construction projects has resulted in a rapidly growing demand to quantitatively predict and evaluate the effects on gene flow among plants and animals in natural habitats. In this study, we evaluated the effects of different road construction scenarios on animal species movement by using the methods of ecological landscape connectivity in the typical regions of Yunnan Province, China. The results showed landscape connectivity levels (Probability of Connectivity (PC)) decreased after road construction and species with lower dispersal abilities were more affected to the subsequent habitat fragmentation. First level roads affected landscape connectivity most significantly. At a distance of $100 \mathrm{~m}$, the PC index decreased more than $50 \%$. Further analysis suggested that the use of landscape connectivity to assess landscape processes revealed the adverse effects on the species movement more effectively compared with the traditional landscape pattern analysis. In addition, we conducted a graph theory and a least-cost modeling discussion, it is obvious that they are powerful tools to represent and analyze landscape networks with respect to related species movement. Network analysis offers a quantitative and simple but effective tool for ecological process assessment and biological conservation on large scales.
\end{abstract}

Keywords: landscape connectivity; road project; landscape network; graph theory; least-cost model

Citation: Liu Shiliang, Deng Li, Chen Liding, Li Junran, Dong Shikui, Zhao Haidi, 2014. Landscape network approach to assess ecological impacts of road projects on biological conservation. Chinese Geographical Science, 24(1): 5-14. doi: 10.1007/s11769-014$0651-\mathrm{z}$

\section{Introduction}

In China, the reduction and fragmentation of natural and semi-natural habitats resulted from agricultural intensification, infrastructure construction, and urbanization, are primary reasons for the current biodiversity crisis (Foley et al., 2005). During the past several decades, China has accomplished many key transportation projects, including large-scale construction of high-speed highway and high-speed railway systems (Liu et al., 2008). By 2025, it is estimated that an additional 20000 $\mathrm{km}$ expressway will be completed to reach a total length of $85000 \mathrm{~km}$ (Li et al., 2010). The interactions between these projects and regional ecosystems are of particular concerns to government, researchers, and the public (Chen et al., 2007).

On large scales, the expansion and extension of road networks causes many ecological effects ( $\mathrm{Li}$ et al., 2010). For example, road development is a primary cause of habitat fragmentation and may result in sudden extinctions of native species. In addition, roads alter landscape structure and function and provide easy access for humans. The ecological results of road construction exist primarily in the change and succession of landscape elements in the road effect zone (Liu et al., 2008). In the United States, a study has shown that roads

Received date: 2013-02-05; accepted date: 2013-08-01

Foundation item: Under the auspices of Nonprofit Environment Protection Specific Project of China (No. 201209029-4)

Corresponding author: LIU Shiliang. E-mail: shiliangliu@bnu.edu.cn

(C) Science Press, Northeast Institute of Geography and Agroecology, CAS and Springer-Verlag Berlin Heidelberg 2014 
and the areas adjacent to their construction zones cover $15 \%-20 \%$ of the total land area (Forman, 1998). Influences of roads on ecological processes can be direct and indirect, and they vary widely from plant community to landscape levels (Hawbaker et al., 2005). In general, the indirect ecological effects of road construction and maintenance are difficult to predict and assess. Therefore, most of current studies have focused on the potential and cumulative effects of roads on ecosystems at the landscape scale.

Assessing ecological effects of road construction on large scales is critical for biodiversity conservation, watershed management and regional planning. However, approaches to quantify ecological effects on these scales are still in dispute among researchers, due to the complicated ecological processes associated with these projects, especially in gene flow within and across landscapes (Gurrutxaga et al., 2010). Currently, several comprehensive concepts were proposed to assess ecological quality, including ecological integrity (Reza and Abdullah, 2011), risk (Liu et al., 2008), security (Chen et al., 2007), and footprint (Yue et al., 2006) on regional scales. On even larger scales, landscape metrics have been used to study landscape pattern changes and fragmentation caused by roads, urban construction, and other human activities (Liu et al., 2008; Li et al., 2010). To assess the ecological effects of major engineering constructions, most studies have relied on an integral assessment of changes of landscape patterns. While landscape patterns and dynamics are direct effects and may be quantified by various landscape metrics (Liu et al., 2008; McGarigal et al., 2012), little attention has been paid to specific indirect effects on ecological processes, including animal movement and gene migration.

In terrestrial systems, the changes in biotic processes due to fragmentation may be accompanied by decreases in landscape connectivity (With and Crist, 1995), which is the degree that the landscape facilitates or impedes movement among resource patches, and it reflects a basic form of interactions between species and their environments (Taylor et al., 1993; Saura and Pascual-Hortal, 2007). Landscape connectivity plays a major role in the maintenance of plant and animal populations, gene flow, and many other landscape functions (Saura and Pascual-Hortal, 2007), which are considered key issues for biodiversity conservation and for the maintenance of natural ecosystem stability and integrity (Crist et al.,
2005). On the landscape scale, connectivity is closely tied to landscape networks. Today, landscape connectivity has attracted considerable attention as natural habitats are lost and fragmented due to urban expansion, transport development and intensive agriculture (Baudry et al., 2003; Frair et al., 2008; Foltête and Giraudoux, 2012).

Modeling landscape connectivity is currently an important issue for ecologists (Foltête et al., 2012). In this paper, a landscape network approach was used to assess the impact of major road projects on landscape processes in biological conservation. The justifications, concepts, methods and procedures related to this approach were discussed. Despite the fact that this new approach is not easy to implement, we believe that it is able to afford researchers detailed information for reconsidering the importance of combining landscape patterns and processes during environmental impact assessments. Specifically, we first introduced the justification of landscape processes for Environmental Impact Assessments (EIAs) of road projects. Next, the methods and a case study of network-based analysis were further elucidated to show the advantages of this technique.

\section{Materials and Methods}

\subsection{Study area}

A typical road project located in Mengla County, Yunnan Province, China was selected as a case study to assess changes in landscape connectivity before and after road construction (Fig. 1). The road selected was built in 2008 as an inter-town road with approximately $40 \mathrm{~km}$ long. With China's road construction policy, more and more major roads have been constructed for the development of the western China. In Yunnan Province, it is estimated that by 2020 , there will be a total of $6000 \mathrm{~km}$ of expressways. The study region is a tropical area and is unique for its climatic features, with complex topography and ecosystems, and high biological diversity. The average annual precipitation is about $1700 \mathrm{~mm}$ and average elevation is about $1000 \mathrm{~m}$ above sea level. Road construction and development create a diverse landscape mosaic and many isolated ecosystems with varied forms of human activity and complex topography.

\subsection{Data and processing}

Landsat TM images (Path/Row: 130/45) in 2008 were 


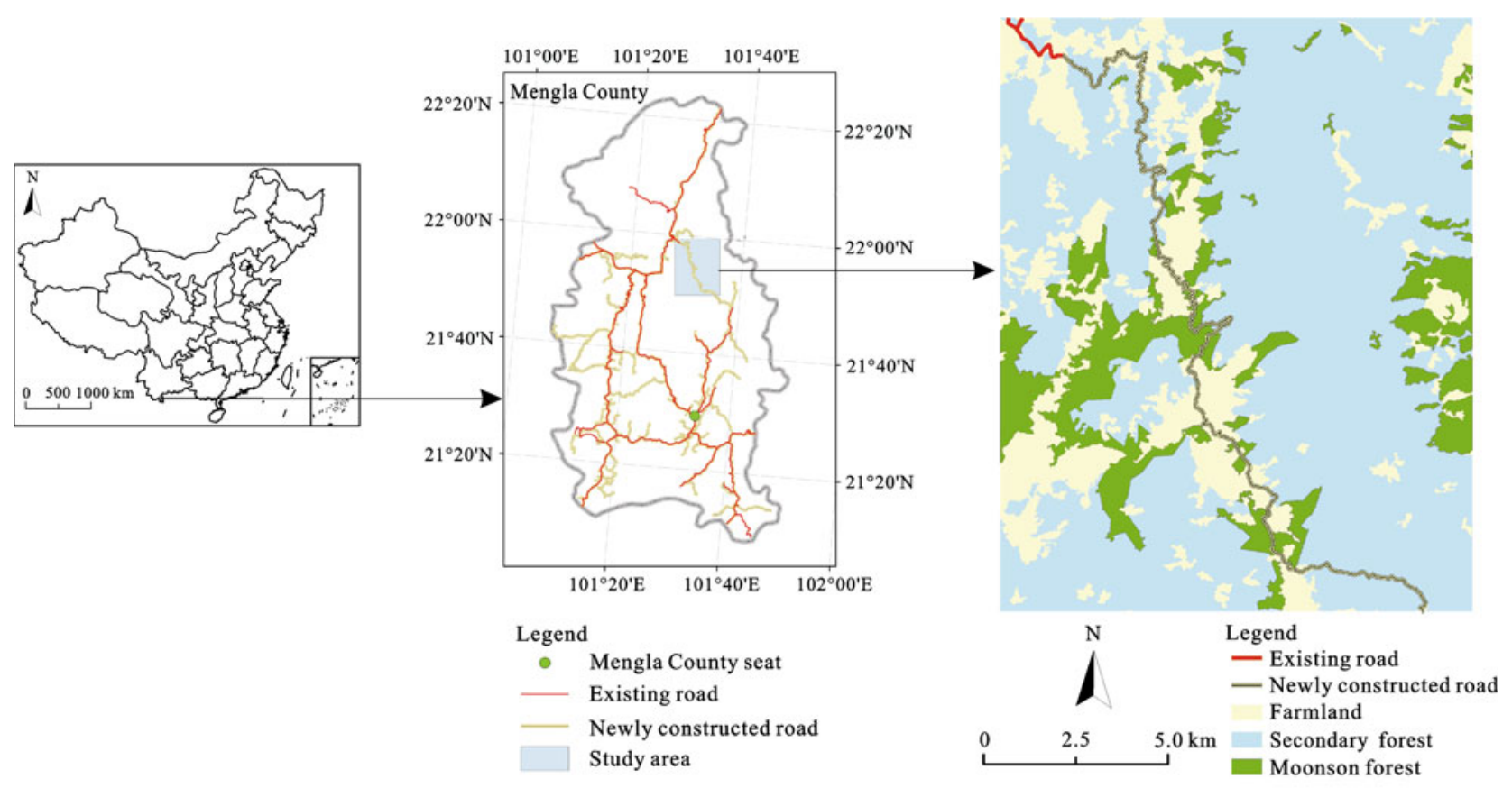

Fig. 1 Location of study area

used for regional land use mapping after they were classified. Information on land use type was extracted by supervised classification with ERDAS software. In this study, as we mainly focused on the monsoon forests as habitat patches, the land uses were classified into three basic types: 1) farmland including dry farmland and paddy land; 2) secondary forest; and 3) monsoon forest (Fig. 1). An accurate assessment of the image was implemented by using ground truth data, and the accuracy of each land cover map was above $80 \%$. The road data were digitized by using the local transportation map in 2008 and were also verified by using the $1: 250000$ scale road database of the National Fundamental Geographical Information Centre in 2002.

\subsection{Methods}

\subsubsection{Theoretical framework of landscape networks} approach for Environmental Impact Assessments (EIA) The ecological effects of road projects are complex yet have not been well-studied, therefore, it is important to quantify these effects, especially on species movement. In China, despite that EIAs have been implemented over the past several decades, no guidelines are available for ecological effects in specific ecological processes.

To assess the ecological effects of major road projects, the first step is to define their disturbance characteristics. Although the road projects may be classified in many ways, for example, according to investment, industry type, and size, on a landscape scale, spatial features of disturbances are the primary concern. Thus, a new classification system was developed according to their shapes, i.e., point, line and area-shaped. Table 1 shows the attributes of different types and their general disturbance features. For landscape patterns, road projects may become a driver of land use change. Different shapes have different orders of ecological effects, including perforation, division, fragmentation, reduction, and disappearance. For landscape functions of inner habitat, isolation, habitat loss and connectivity, lineshaped projects that can form a network affect landscape processes most in terrestrial ecosystems. The landscape network approach with connectivity calculation may be a new way to assess these effects. This approach can be accompanied by other EIA steps, such as field investigation and remote sensing image interpretation.

Figure 2 shows a general procedure of a landscape network approach for EIAs. For the connectivity analysis, habitat types for different land uses should be selected, followed by the determination of key species or scenarios defined for the movement of different species. Based on graph theory and landscape network, a landscape connectivity index may be calculated before and after project construction. Also, the patch importance within the landscape can be evaluated and used for comparison. 
Table 1 Classification of major road projects and attributes of their ecological effects

\begin{tabular}{|c|c|c|c|}
\hline Feature & Point shape & Line shape & Area shape \\
\hline Example & Dam, hydropower station, factory & Railway, roads, oil or gas pipeline & $\begin{array}{l}\text { Land consolidation, development } \\
\text { zones, urbanization }\end{array}$ \\
\hline Area & Small & Relatively small & Large \\
\hline Analogues in GIS & Point feature & Polyline feature & Polygon feature \\
\hline $\begin{array}{l}\text { Pattern alteration } \\
\text { effect }\end{array}$ & $\begin{array}{l}\text { Perforation }>\text { division }>\text { fragmentation }> \\
\text { disappearance }\end{array}$ & $\begin{array}{l}\text { Division }>\text { fragmentation }>\text { reduction }> \\
\text { disappearance }\end{array}$ & $\begin{array}{l}\text { Perforation }>\text { reduction }>\text { disappearance }> \\
\text { fragmentation }>\text { division }\end{array}$ \\
\hline Effect zone shape & $\begin{array}{l}\text { Approximately circle in terrestrial region; } \\
\text { Upstream and downstream in riverine system }\end{array}$ & $\begin{array}{l}\text { Buffer zone along line; } \\
\text { Irregular at large scale }\end{array}$ & $\begin{array}{l}\text { Interior effect }>\text { external effect, buffers } \\
\text { of polygon shape }\end{array}$ \\
\hline Patch number & Little change & Increase significantly & $\begin{array}{l}\text { Little change at regional scale, while } \\
\text { decreases inside }\end{array}$ \\
\hline Perimeter & Little change & Increase significantly & Decreases inside \\
\hline Patch size & Little change & Decrease & Increases inside \\
\hline Inner habitat & No inner habitat & Decreases greatly & Almost vanishes inside \\
\hline Isolation & Increases & Increases greatly & Little change \\
\hline Habitat loss & Increases greatly, mainly in rivers & Increases greatly & Increases greatly \\
\hline Distribution & Random or along rivers & Network & Random \\
\hline Connectivity & Decreases significantly & Decreases significantly & $\begin{array}{l}\text { Little change at regional scale, almost } \\
\text { vanishes inside }\end{array}$ \\
\hline
\end{tabular}

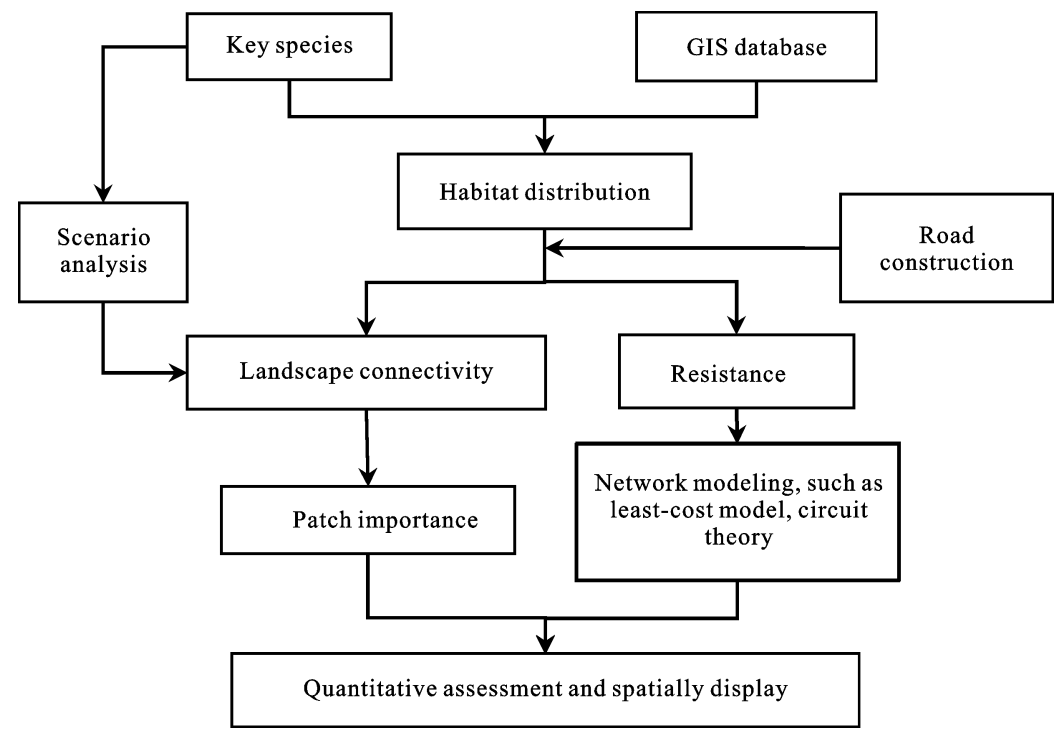

Fig. 2 General procedure of landscape network for assessing impact of road projects on species movement

When analyzed on a broad scale, the modeling of landscape networks provides an approach to obtain information about landscape connectivity (Foltête and Giraudoux, 2012). The connections among habitat patches are best characterized through a probabilistic model, in which the dispersal among habitat patches is typically modeled as a decreasing function of interpatch Euclidean or effective distance (Saura and PascualHortal, 2007). Actually, landscape connectivity reflects species movement within the landscape network.

Currently, cost distances, rather than Euclidian dis- tances, were used increasingly to achieve a more realistic measure of animal movement, on the basis of resistance values assigned to each landscape class (Foltête $e t$ $a l ., 2008)$. The least-cost model originates from graph theory, and integrates detailed geographical information with organisms' behavioral characteristics in the landscape. For the least-cost modeling, a source layer and a friction/resistance layer form the input of the model. The source layer of a single patch or a complex of patches indicates the habitat patches from which the connectivity is calculated. The resistance layer indicates 
both the resistance value and the geographical position and orientation of all relevant landscape elements (Adriaensen et al., 2003). Thus, the effective distance can be calculated and compared before and after major engineering construction. The results of this approach are both spatially explicit and quantitative.

Because of their inherent advantages in the consideration of connectivity relationships, we suggest that landscape network analysis offers a simple, but effective tool to search for key segments (or junctions) in EIA procedures and environmental management.

\subsubsection{Calculation of landscape connectivity}

As discussed above, by using graph theory for landscape network analysis has been established as a promising way to explore landscape or habitat connectivity efficiently (Erös et al., 2011). For animal movement, the effects on landscape connectivity were evaluated based on the 'Probability of Connectivity (PC)' index. The PC index is defined as the probability that two animals randomly placed within a landscape will fall into interconnected areas of habitat (Pascual-Hortal and Saura, 2006). The PC index has been applied to calculate global connectivity by separating the effects of area, potential dispersal flux and potential crossing (Saura et al., 2011). Thus, the PC index considers ecological processes and how road construction would affect animal movements. The index is given by:

$$
P C=\frac{\sum_{i=1}^{n} \sum_{j=1}^{n} a_{i} a_{j} p_{i j}^{*}}{A_{L}^{2}}
$$

where $a_{i}$ and $a_{j}$ are the areas of the resource patches $i$ and $j$, and $A_{L}$ is the total landscape area of the study region; $p_{i j}^{*}$ is defined as the maximum product probability of all possible paths between patches $i$ and $j$ (includeing single-step paths). We used Conefor Sensinode 2.2 (Saura and Torné, 2009) to calculate the PC indices in this study. Also, the variation of PC index (dPC) after removing that patch $i$ from the landscape was calculated. The $\mathrm{dPC}$ value can reveal the importance of patches, i.e., the ranking of habitat patches by their contributions to total landscape connectivity and habitat availability (Saura et al., 2011). Detailed calculation procedures are given in by Saura and Pascual-Hortal (2007) and Saura and Torné (2009).

Monsoon forests were selected as resource patches for small mammals according to the local conditions. For road construction, we assumed the road would be improved; thus, three road construction scenarios were set as: 1) inter-town road (third-class road); 2) road connecting two cities in different counties (second-class road); and 3) national road (first-class road). For the three types of road construction, we set different buffer zones, as follows: third-class road, $100 \mathrm{~m}$; second-class road, $250 \mathrm{~m}$; and first-class road, $500 \mathrm{~m}$ (Liu et al., 2008). Also, scenario analysis was used for different species dispersal abilities. We set 100, 200, 500, 1000, 2000 and $3000 \mathrm{~m}$ for animal movements, and a total of 18 scenarios were used for the landscape connectivity analysis.

Fragstats 4.1 (McGarigal et al., 2012) was used to calculate landscape pattern metrics. The fragmentation effect was quantified by reductions in area, patch shape and diversity due to the presence and intersections by roads. The selected landscape pattern indices included: splitting index (SPLIT), perimeter-area fractal dimension (PAFRAC), and Shannon's diversity index (SHDI). These indices were used to described fragmentation, shape, and diversity with respect to landscape pattern changes under different road construction scenarios. Finally, the efficiencies of these two different methods of landscape pattern and landscape connectivity were compared.

\section{Results and Analyses}

\subsection{Landscape connectivity change under differ- ent scenarios}

Figure 3 shows the landscape connectivity changes at different dispersal distances. The results showed that the $\mathrm{PC}$ values under these dispersal scenarios increased with dispersal distance. PC values decreased after road construction, indicating that connectivity levels declined. Studies have showed that species with low dispersal abilities, which often constrained them to a limited number of habitat patches, were especially vulnerable to habitat fragmentation. By comparison, changes in connectivity caused by road construction had the least effect on animals with the ability to disperse greater distances. Also, Fig. 3 shows that landscape connectivity has been affected by the road level substantially. In particular, under the first level of road construction, PC indices were lower than under the second and third levels of construction. 


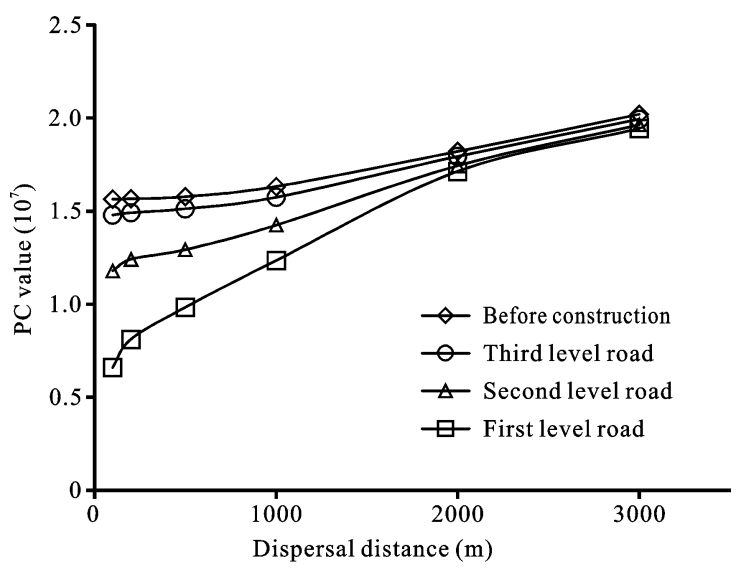

Fig. 3 Changes in landscape connectivity (PC value) of different road scenarios for dispersal distances of 100, 200, 500, 1000, 2000 and $3000 \mathrm{~m}$

Figure 4 shows the decrease ratios of the different road levels on landscape connectivity. It is clear that first level roads affect landscape connectivity most significantly at all dispersal distances studied where the PC index decreased more than $50 \%$ for animals' ability to disperse at a distance of $100 \mathrm{~m}$. For the second level road, the ratio dropped to around $20 \%$ at a dispersal distance less than $500 \mathrm{~m}$. However, the decrease ratios for the existing inter-town (third level) road construction ranged from $1.5 \%$ to $5.5 \%$, demonstrating that the least disruptive construction had the least hazard effect on connectivity.

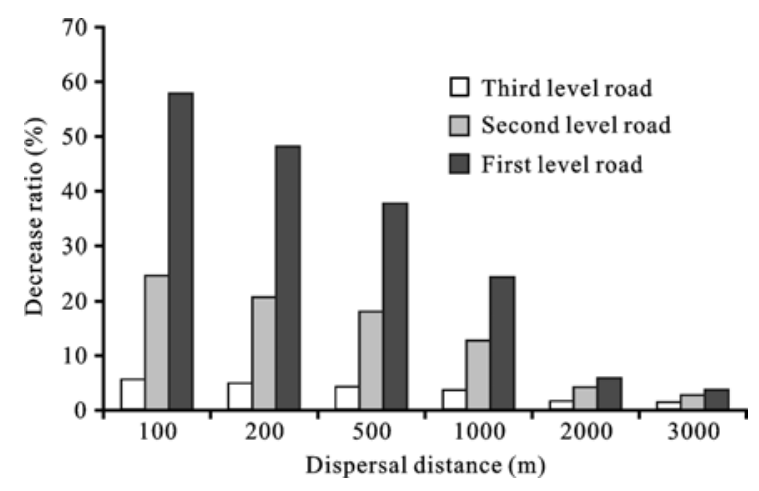

Fig. 4 Decrease ratios of different level roads on landscape connectivity

\subsection{Change of importance of patches for land- scape connectivity}

Considering the changes in the matrix due to road construction, the variations in the landscape connectivity may be slightly but significantly larger in certain patches, which means the importance change could be more specified to show the patch contribution rate to the whole connectivity at patch scale. The ranking order of dPC value over the landscape indicates the importance of patches in sustaining landscape connectivity under the influence of road construction. The values were calculated to show the importance variations before and after road construction for each patch. The importance change ratios were classified into three levels as increase (> $5 \%)$, little change $(-5 \%-5 \%)$ and decrease $(<-5 \%)$.

Figure 5 shows the changes in the importance of patches after road construction (scenario of $2000 \mathrm{~m}$ dispersal distance under the inter-town road construction). Our results showed the importance at patch scale changed markedly after road construction. In the middle of the road, patches were influenced most severely, while the importance of patches far from the road increased following construction. The patches in middle part as key steppingstone patches were severely destroyed. Subsequently, the maximum probability of species movement between any two patches was also reduced.

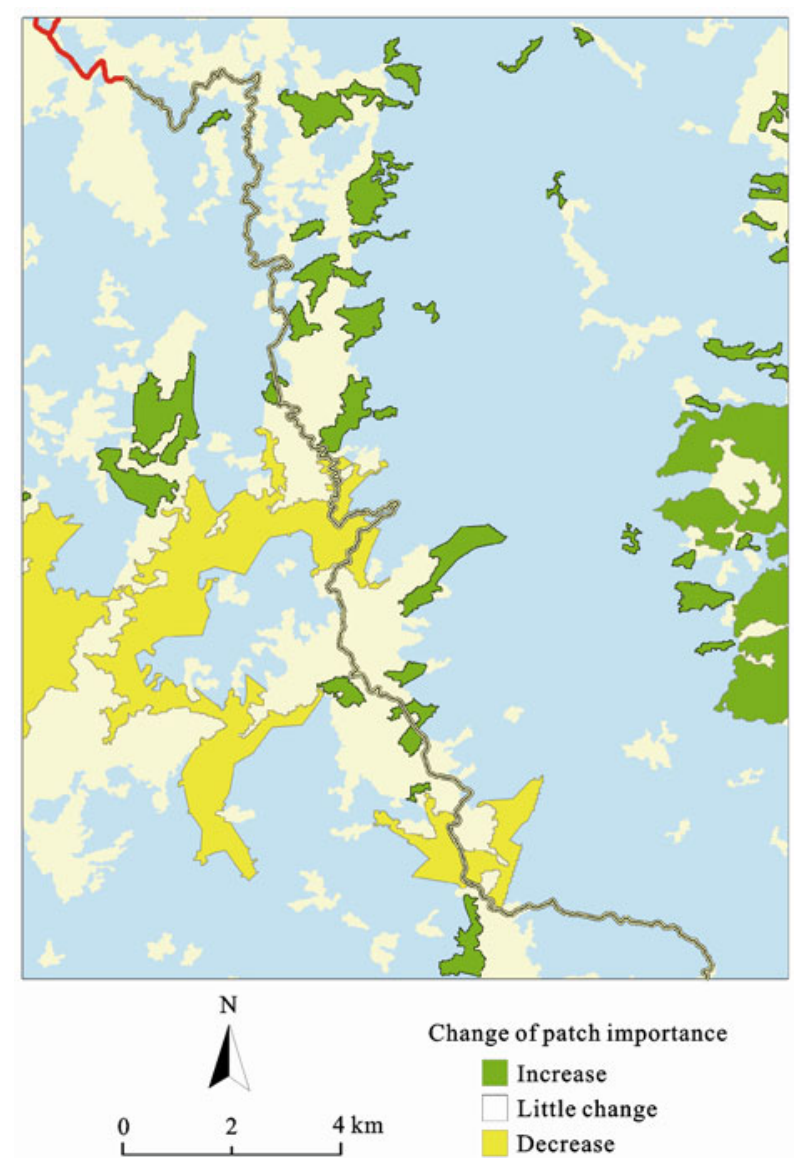

Fig. 5 Changes of patch importance after third level road construction at dispersal distance of $2000 \mathrm{~m}$ 
3.3 Comparison of landscape pattern and landscape connectivity

Figure 6 shows the decrease ratios of different landscape pattern index after road construction. The results showed that the SPLIT index decreased after third level road construction, while it increased after second and first level road construction. As SPLIT index is based on the cumulative patch area distribution and is interpreted as the effective mesh number, the variations indicated road could lead to 'isolation effect'. In this study area, the SPLIT values ranged from $-0.5 \%$ to $0.2 \%$, which might be attributed to the relatively low road density. For the PAFRAC, the decrease ratio decreased gradually from the third to the first level road construction. The PAFRAC value reflects shape complexity across a range of patch sizes. It is clear that the patch perimeters would increase after road construction and third level road had largest effect due to its largest total length. The SHDI index remained unchanged as the areas of different land use types change little. Compared to landscape connectivity index, landscape pattern indexes indicating fragmentation, shape, and diversity were relatively low, ranging from $-2.0 \%$ to $2.0 \%$. Pattern analysis lacks ecological meaning and the change trend of different indices is not similar for different level roads. For line-shaped features, the selected indices are neither suitable nor able to reflect the actual changes.

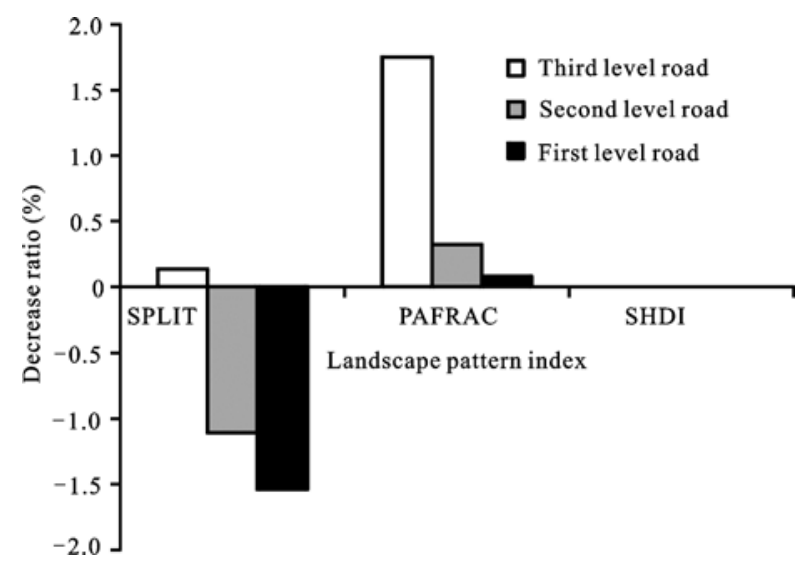

Fig. 6 Decrease ratios of different road levels on landscape pattern

\section{Discussion}

\subsection{Feasibility of landscape connectivity to assess effect of road projects on species movement}

Although road construction projects are often short-term, the disturbance could be intense and the potential effects on species movement may be long-term. As field observations of animal species take a considerable amount of time, they are usually insufficient to provide a meaningful overview for an EIA project. However, the scenario analysis that considers animal movements can be expressed directly by changes in landscape connectivity, it is feasible to assess the potential effects of such changes. This study showed that road construction affects the landscape connectivity greatly and the decrease ratios of landscape connectivity could reach more than $50 \%$ for animals with lower disperse ability.

Graph theory is a framework that has been widely applied in geography (Bunn et al., 2000). Urban and Keitt (2001) have introduced landscape-level graph theory to ecologists. Graph theoretic or network-based approaches can provide a quantitative and complementary view of landscape changes related to road construction no matter that landscape networks may be either spatially explicit or latent. Recently, graph theory has become an interesting approach to depict landscape connectivity (Minor and Urban, 2007; 2008). Graphs can be used to represent spatial relationships among habitat patches and, for focal species, among individuals in landscapes (Galpern et al., 2011). Based on a simplified representation of the landscape, nodes represent habitat patches and link the potential species flux between them (Bunn et al., 2000; Urban et al., 2009). Thus, landscape graph analysis can be used to quantify potential connectivity by means of connectivity metrics (Foltête and Giraudoux, 2012).

This study revealed that compared with other landscape indices, the PC index has advantages in responding to different relevant changes occurring in the landscape and identifying the most critical landscape elements effectively for the maintenance of overall landscape connectivity (Pascual-Hortal and Saura, 2006). Only landscape pattern comparison could not give a clear picture of the ecological effects of the construction of major road projects. Though the inherent mechanism between landscape connectivity and habitat loss or species extinction remains unclear, the connectivity changes before and after major road construction calculated by scenario analysis do provide a quantitative description of the effects of construction projects on species movement. Thus, based on our study, we suggest that pattern and process may be integrated to a certain extent. Ac- 
cording to the results, graph theory with landscape connectivity has the following three merits in assessing environmental effects: 1) integrating landscape pattern with process (species movement); 2) indicating the 'fragmentation-barrier' effect of line-shaped projects effectively; 3) scenario analysis (different dispersal distances) can be used for multi-purpose assessments.

In the assessment of the potential effects of major road projects, one critical issue is the identification of the zone affected. The habitat fragmentation caused by roads in the study area generally had negative effects on the landscape with respect to sustaining connectivity, especially on those patches intersected directly by roads (Fu et al., 2010). Traditional field investigation encounters many difficulties for identification the zone affected and the patch importance change, while the major advantage of the network approach was the ability to clearly reveal the connectivity change and the patch importance at local and region scale (Zetterberg et al., 2010). Knowledge accrued from landscape network analysis, in combination with the importance and spatial extent of ecological nodes and links, are critical to identify areas of high ecological value that are in need of protection (Zetterberg et al., 2010; Galpern et al., 2011). Our case study provided preliminary results of connectivity analysis, although it is somewhat atypical, as the road constructed is not a key project. However, further research on specific species and least-cost modeling should be pursued.

\subsection{Implications of least-cost distance modeling and circuit theory for landscape network}

In landscape ecology, spatial distance is of primary importance to the concepts of connectivity and fragmentation (Foltête et al., 2008). Distance is a basic factor in animal movement. The distance available for movement can be thought of as wildlife corridors or potential corridors within landscapes. In reality, landscape network acts as ecological corridors for different species. Costdistance ideas are based on cost surfaces built for a set of target species associated with the dominant habitats of a region. Least-cost paths are then used to identify zones of probable connection between habitats (Gurrutxaga et al., 2010). Graph theoretic approaches with least-cost modeling have received increased interest recently in landscape planning and conservation in terrestrial ecosystems because these approaches facilitate the effective modeling of connectivity among habitats
(Foltête et al., 2008).

Obviously, major road projects constitute great resistance to species movement, and thus, they will change movement routes and the landscape network pattern directly or potentially. Given a certain region and species, assuming the resistance value for a different landscape class remains stable, the least-cost distance between habitats could be derived easily by GIS and shown explicitly on a map. This also lays the foundation for a scientific approach to corridor design. By comparing least-cost distance caused by major road projects, it is possible to quantify the ecological effects with pattern-process meanings. Further, during EIAs of major road projects, least-cost distance analysis could be incorporated with connectivity analysis, which would assist in identifying the most critical landscape elements for the maintenance of overall connectivity (PascualHortal and Saura, 2007).

The least-cost modeling can only identify a single optimal route, rather than the multiple possible routes to the effective distance. It has also been criticized for potentially unrealistic assumptions, for example, that the dispersing animal has prior knowledge of its surroundings and chooses the least costly path based on this knowledge (Baguette and van Dyck, 2007). Concepts and algorithms from electrical circuit theory have been adopted to address these problems. The isolation-byresistance model or circuit theory complements least-cost path approaches because it considers the effects of all possible pathways across a landscape simultaneously (McRae, 2006). The isolation-by-resistance model, which is based on calculations of the costs of movement across a surface having resistance, is becoming more widely adopted. This method offers a conceptual model in which landscape resistance is an analogue of electrical resistance, and the movements of individuals and flow of genes are analogues of electrical current.

Least-cost modeling and circuit theory can provide insights into the relationships between species dispersal and landscape characteristics. Such models can be useful for predicting ecological and genetic effects of spatial heterogeneity and landscape change and also for assessing the effects of road projects on gene flow for plant and animal species. Though scale variation will affect the precision of location and orientation of linear elements of effective distances, scenario analysis can be compared in a quantitative way at the landscape level as well as for individual grid cells. 


\section{Conclusions}

In this paper, we described the theoretical framework of the landscape network approach for EIA by comparing the ecological effects of road projects with other road projects according to their spatial shapes. Landscape network procedures that are used to assess the ecological effects of major road projects were presented. Taking a typical region in Yunnan Province, southwestern China as a case, the effects of different level roads on landscape connectivity were investigated. Using scenario analysis, we compared the PC index change at different dispersal distances. The result showed that PC values increased with dispersal distance. However, landscape connectivity with shorter dispersal distances were affected more significantly by road construction than longer dispersal distances. Also, higher level roads affected PC indexes more greatly than lower level roads at all dispersal distances studied. It is calculated that the PC index would decrease more than $50 \%$ at a dispersal distance of $100 \mathrm{~m}$. The dPC values indicating patch importance changed markedly after road construction. Further, traditional landscape pattern indexes including SPLIT, PAFRAC, SHDI index were calculated to compare the results of PC values. The results showed that landscape pattern indexes were not able to reflect the real ecological change due to road construction.

Our case study showed the effectiveness of landscape connectivity based on graph theory. Scenario analysis based on different species dispersal distances can be used for a general comparison. The importance of different patches may be derived by connectivity analysis. The joint consideration of landscape networks and major road projects may present a great challenge, but it could offer a more valid form of quantitative assessment than pattern analysis. Therefore, we believe there is a need for more intensive testing and application of landscape network approaches in EIAs for major road projects, as this approach has the potential to significantly increase our ability to understand ecological processes within and across habitats, especially on large scales.

\section{References}

Adriaensen F, Chardon J P, De Blust G et al., 2003. The application of 'least-cost' modelling as a functional landscape model. Landscape and Urban Planning, 64(4): 233-247. doi: 10.1016/S0169-2046(02)00242-6
Baguette M, van Dyck H, 2007. Landscape connectivity and animal behavior: Functional grain as a key determinant for dispersal. Landscape Ecology, 22: 1117-1129. doi: 10.1007/ s10980-007-9108-4

Baudry J, Burel F, Aviron S et al., 2003. Temporal variability of connectivity in agricultural landscapes: Do farming activities help? Landscape Ecology, 18(3): 303-314. doi: 10.1023/ A: 1024465200284

Bunn A G, Urban D L, Keitt T H, 2000. Landscape connectivity: A conservation application of graph theory. Journal of Environmental Management, 59(4): 265-278. doi: 10.1006/jema. 2000.0373

Chen Lingding, Lyu Yihe, Tian Huiying et al., 2007. Principles and methodology for ecological rehabilitation and security pattern design in key project construction. Chinese Journal of Applied Ecology, 18: 674- 680. (in Chinese)

Crist M R, Wilmer B, Aplet G H, 2005. Assessing the value of roadless areas in a conservation reserve strategy: Biodiversity and landscape connectivity in the northern Rockies. Journal of Applied Ecology, 42(1): 181-191. doi: 10.1111/j.1365-2664. 2005.00996.x

Erős T, Schmera D, Schick R S, 2011. Network thinking in riverscape conservation-A graph-based approach. Biological Conservation, 144(1): 184-192. doi:10.1016/j.biocon.2010.08. 013

Foley J A, Defries R, Asner G P et al., 2005. Global consequences of land use. Science, 309(5734): 570-574. doi: $10.1126 /$ science. 1111772

Foltête J C, Berthier K, Cosson J F, 2008. Cost distance defined by a topological function of landscape. Ecological Modelling, 210(1-2): 104-114. doi: 10.1016/j.ecolmodel.2007.07.014

Foltête J C, Clauzel C, Vuidel G, 2012. A software tool dedicated to the modelling of landscape networks. Environmental Modelling \& Software, 38: 316-327. doi: 10.1016/j.envsoft.2012.07. 002

Foltête J C, Giraudoux P, 2012. A graph-based approach to investigating the influence of the landscape on population spread processes. Ecological Indicators, 18: 684-692. doi: 10.1016/j.ecolind.2012.01.011

Forman R T T, 1998. Roads and their major ecological effects. Annual Review of Ecology and Systematics, 29: 207-231. doi: 10.1146/annurev.ecolsys.29.1.207

Frair J L, Merrill E H, Beyer H L et al., 2008. Thresholds in landscape connectivity and mortality risks in response to growing road networks. Journal of Applied Ecology, 45(5): 1504-1513. doi: 10.1111/j.1365-2664.2008.01526.x

Fu Wei, Liu Shiliang, Degloria S D et al., 2010. Characterizing the "fragmentation-barrier" effect of road networks on landscape connectivity: A case study in Xishuangbanna, Southwest China. Landscape and Urban Planning, 95(3): 122-129. doi: 10.1016/j.landurbplan.2009.12.009

Galpern P, Manseau M, Fall A, 2011. Patch-based graphs of landscape connectivity: A guide to construction, analysis and application for conservation. Biological Conservation, 144(1): 44-55. doi: 10.1016/j.biocon.2010.09.002

Gurrutxaga M, Lozano P J, del Barrio G, 2010. GIS-based 
approach for incorporating the connectivity of ecological networks into regional planning. Journal for Nature Conservation, 18(4): 318-326. doi: 10.1016/j.jnc.2010.01.005

Hawbaker T J, Radeloff V C, Hammer R B et al., 2005. Road density and landscape pattern in relation to housing density, and ownership, land cover, and soils. Landscape Ecology, 20: 609-625. doi: 10.1007/s10980-004-5647-0

Li T, Shilling F, Thorne J et al., 2010. Fragmentation of China's landscape by roads and urban areas. Landscape Ecology, 25: 839-853. doi: 10.1007/s10980-010-9461-6

Liu S L, Cui B S, Dong S K et al., 2008. Evaluating the influence of road networks on landscape and regional ecological risk-A case study in Lancang River Valley of Southwest China. Ecological Engineering, 34(2): 91-99. doi: 10.1016/ j.ecoleng.2008.07.006

McGarigal K, Cushman S A, Ene E, 2012. FRAGSTATS v4: Spatial Pattern Analysis Program for Categorical and Continuous Maps. Computer software program produced by the authors at the University of Massachusetts, Amherst. Available at: http://www.umass.edu/landeco/research/fragstats/ fragstats.html

McRae B H, 2006. Isolation by resistance. Evolution, 60(8): 1551-1561. doi: 10.1111/j.0014-3820.2006.tb00500.x

Minor E S, Urban D L, 2007. Graph theory as a proxy for spatially explicit population models in conservation planning. Ecological Applications, 17(6): 1771-1782. doi: 10.1890/061073.1

Minor E S, Urban D L, 2008. A graph-theory framework for evaluating landscape connectivity and conservation planning. Conservation Biology, 22(2): 297-307. doi: 10.1111/j.15231739.2007.00871.x

Pascual-Hortal L, Saura S, 2006. Comparison and development of new graph-based landscape connectivity indices: Towards the priorization of habitat patches and corridors for conservation. Landscape Ecology, 21(7): 959-967.doi: 10.1007/s10980-0060013-z

Pascual-Hortal L, Saura S, 2007. Impact of spatial scale on the identification of critical habitat patches for the maintenance of landscape connectivity. Landscape and Urban Planning, 83
(2-3): 176-186. doi: 10.1016/j.landurbplan.2007.04.003

Reza M I H, Abdullah S A, 2011. Regional Index of Ecological Integrity: A need for sustainable management of natural resources. Ecological Indicators, 11: 220-229. doi: 10.1016/ j.ecolind.2010.08.010

Saura S, Estreguil C, Mouton C et al., 2011. Network analysis to assess landscape connectivity trends: Application to European forests (1990-2000). Ecological Indicators, 11(2): 407-416. doi: 10.1016/j.ecolind.2010.06.011

Saura S, Pascual-Hortal L, 2007. A new habitat availability index to integrate connectivity in landscape conservation planning: Comparison with existing indices and application to a case study. Landscape and Urban Planning, 83(2-3): 91-103. doi: 10.1016/j.landurbplan.2007.03.005

Saura S, Torné J, 2009. Conefor Sensinode 2.2: A software package for quantifying the importance of habitat patches for landscape connectivity. Environmental Modelling \& Software, 24(1): 135-139. doi: 10.1016/j.envsoft.2008.05.005

Taylor P D, Fahrig L, Henein K et al., 1993. Connectivity is a vital element of landscape structure. Oikos, 68(3): 571-573. doi: $10.2307 / 3544927$

Urban D L, Keitt T H, 2001. Landscape connectivity: A graph-theoretic perspective. Ecology, 82(5): 1205-1218. doi: 10.1890/0012-9658(2001)082[1205:LCAGTP]2.0.CO;2

Urban D L, Minor E S, Treml E A et al., 2009. Graph models of habitat mosaics. Ecology Letters, 12(3): 260-273. doi: 10.1111/ j.1461-0248.2008.01271.x

With K A, Crist T O, 1995. Critical thresholds in species' responses to landscape structure. Ecology, 76(8): 2446-2459. doi: $10.2307 / 2265819$

Yue D, Xu X, Li Z et al., 2006. Spatiotemporal analysis of ecological footprint and biological capacity of Gansu, China 1991-2015: Down from the environmental cliff. Ecological Economics, 58(2): 393-406. doi: 10.1016/j.ecolecon.2005.07. 029

Zetterberg A, Mörtberg U M, Balfors B, 2010. Making graph theory operational for landscape ecological assessments, planning, and design. Landscape and Urban Planning, 95(4): 181191. doi: 10.1016/j.landurbplan.2010.01.002 